\title{
Variations
}

Variations

Revue internationale de théorie critique

16 | 2012

Tahrir is here !

\section{Bernard Hours, Monique Selim, Anthropologie politique de la globalisation}

\section{Louis Moreau de Bellaing}

\section{(2) OpenEdition}

1 Journals

Édition électronique

URL : http://journals.openedition.org/variations/123

DOI : 10.4000/variations. 123

ISSN : 1968-3960

Éditeur

Les amis de Variations

Édition imprimée

Date de publication : 16 janvier 2012

\section{Référence électronique}

Louis Moreau de Bellaing, «Bernard Hours, Monique Selim, Anthropologie politique de la

globalisation », Variations [En ligne], 16 | 2012, mis en ligne le 20 février 2012, consulté le 22 septembre 2020. URL : http://journals.openedition.org/variations/123 ; DOI : https://doi.org/10.4000/variations. 123

Ce document a été généré automatiquement le 22 septembre 2020.

Les ami•e•s de Variations 


\title{
Bernard Hours, Monique Selim, Anthropologie politique de la globalisation
}

\author{
Louis Moreau de Bellaing
}

\section{RÉFÉRENCE}

Bernard Hours, Monique Selim, Anthropologie politique de la globalisation,

L'Harmattan, Paris, 2010

\section{NOTE DE L'ÉDITEUR}

Première publication sur www.theoriecritique.com, « Tahrir is here !», 16 janvier 2012, pp. 153-154

1 Le livre est important à plus d'un titre. Il marque, à notre avis, une rupture en anthropologie, rupture amorcée par les précédents ouvrages des auteurs et de quelques autres, mais rupture ici affirmée. La globalisation s'est faite, s'ajoutant à une mondialisation qui n'est pas de même nature

2 Par exemple la mondialisation de la communication (transports, informatique) ne peut être analogisée avec la globalisation des circuits du marché capitaliste et l'apparition d'un socialisme de marché dans les anciens totalitarismes, ni avec la toute-puissance d'une caste économique dont les tenants, d'une nation à l'autre, tout en se concurrençant férocement, savent défendre leurs intérêts communs.

3 Il ne s'agit donc plus, nous disent Monique Selim et Bernard Hours, pour les anthropologues, de se livrer à leurs études exotiques, culturalistes, pour connaître les sociétés du lointain par rapport à l'Occident. Il s'agit bel et bien de rechercher les nouvelles normes qui se mettent en place, dans des ensembles sociaux (nationalitaires 
ou non), pour donner toute sa portée et sa permanence à la globalisation du capitalisme. On ne parle plus d'impérialisme, comme en parlait Lénine montrant comment les voies de chemins de fer s'exportant assuraient la mainmise des pays colonisateurs sur ceux colonisés. Désormais, c'est simultanément, depuis que le mur de Berlin, c'est-à-dire le rideau de fer est détruit, un capitalisme sans limites qui s'établit dans le monde entier, se substituant, là où il existait, à un collectivisme qui avait fait la preuve à la fois de son inefficacité et de la cruauté qu'il exigeait: "Le projet d'une gouvernance sécuritaire et globalisée privilégie une reproduction paisible de l'économie de marché » écrivent les auteurs en quatrième de couverture.

4 Le problème, c'est celui des laissés pour compte, à des degrés divers de dénuement et de déconsidération. Ils sont les plus nombreux, en Asie, en Afrique, en Amérique centrale et du Sud. Aux plus démunis, aux plus opprimés, sans que pour autant ils y trouvent leur dignité d'êtres humains, les processus de globalisation, tout en assurant l'emprise capitaliste, imposent des normes « dans les domaines de la santé, du travail, de la sécurité, de l'éthique et de la morale humanitaire » (quatrième de couverture). Il y a en quelque sorte un management globalisé qui accompagne le capitalisme globalisé. La santé n'est plus une affaire de société, mais d'Etats-nations par les grandes entreprises de production de médicaments. Le travailleurs qualifié, protégé, pris dans des réseaux où il peut s'individualiser, laisse derrière lui le précaire, le chômeur, qu'il soit provisoire ou permanent. Une politique de la compassion, mais très peu de la solidarité et encore moins de la reconnaissance d'une humanité commune ne prend pas en compte les légitimations sociales et politiques que produisent les groupes et les individus. Il s'agit de sécuriser en bloc, non de contribuer à une apparition de l'imprévu.

5 Les nouvelles normes sont investies dans des figures idéologiques, sinon imaginaires, comme la femme, l'étranger, le peuple dit autochtone, le postcolonisé, le handicapé, le pauvre (qui n'est, par ailleurs, le plus souvent, que le misérable tel qu'on peut le voir, en moindre nombre, en Occident). La démocratie se trouve dévoyée de sa finalité, les droits de l'homme sont non seulement bafoués, mais idéologisés par une narrativisation sans sujets sociaux et politiques, par une moralisation de masses que le manager technocrate, mais aussi paternaliste, manie avec habileté, dissimulant ainsi ce que sont des femmes, des étrangers, des populations d'anciens colonisé ou leurs descendants, des handicapés, des misérables, stigmatisés," exploités et opprimés, à l'aide d'idéologies de raccroc (racisme, sexisme, etc.), dans leur existence matérielle et sociale, mais vivant néanmoins leur vie individuelle et collective.

Bernard Hours montre comment l'idée de développement - lancée par Rostow et dont, dans les années soixante, Aron lui-même se moquait dans ses séminaires - a fait son chemin, avec celles de pays non-développés et de pays en voie de développement. A ces idées désormais obsolètes avec la globalisation du capitalisme, s'est substituée celle de développement durable, panacée universelle dont seuls les écologistes semblent tirer quelques projets de protection nécessaire de la nature et de la planète. Bernard Hours montre également comment la bonne volonté des O.N.G. ou la mise en place de microcrédits ne parvient guère à éradiquer la misère. Le cas de l'Ouzbékistan est particulièrement exemplaire.

7 Monique Selim montre l'écart entre les logiques sociales, les normes globales, les figurations toutes largement idéologisées et la réalité vécue par des ouvriers et ouvrières de Hanoï, réalité du concret, mais aussi de l'imaginaire avec le culte des 
morts. Elle le montre également au Laos où le désastre économique pour la population a fait réapparaître le culte des génies.

8 Un livre salubre, pour une anthropologie du présent qui ne sacrifie pas l'avenir.

\section{AUTEURS}

\section{LOUIS MOREAU DE BELLAING}

Né en 1932, ancien professeur des universités en sociologie. Ses recherches portent sur l'autorité, la légitimation, le pouvoir et sur la population minoritaire des SDF. 